\title{
The clinical and prognostic value of motor abnormalities in psychosis, and the importance of instrumental assessment
}

Citation for published version (APA):

van Harten, P. N., Walther, S., Kent, J. S., Sponheim, S. R., \& Mittal, V. A. (2017). The clinical and prognostic value of motor abnormalities in psychosis, and the importance of instrumental assessment. Neuroscience and Biobehavioral Reviews, 80, 476-487. https://doi.org/10.1016/j.neubiorev.2017.06.007

Document status and date:

Published: 01/09/2017

DOI:

10.1016/j.neubiorev.2017.06.007

Document Version:

Publisher's PDF, also known as Version of record

\section{Document license:}

Taverne

\section{Please check the document version of this publication:}

- A submitted manuscript is the version of the article upon submission and before peer-review. There can be important differences between the submitted version and the official published version of record.

People interested in the research are advised to contact the author for the final version of the publication, or visit the DOI to the publisher's website.

- The final author version and the galley proof are versions of the publication after peer review.

- The final published version features the final layout of the paper including the volume, issue and page numbers.

Link to publication

\footnotetext{
General rights rights.

- You may freely distribute the URL identifying the publication in the public portal. please follow below link for the End User Agreement:

www.umlib.nl/taverne-license

Take down policy

If you believe that this document breaches copyright please contact us at:

repository@maastrichtuniversity.nl

providing details and we will investigate your claim.
}

Copyright and moral rights for the publications made accessible in the public portal are retained by the authors and/or other copyright owners and it is a condition of accessing publications that users recognise and abide by the legal requirements associated with these

- Users may download and print one copy of any publication from the public portal for the purpose of private study or research.

- You may not further distribute the material or use it for any profit-making activity or commercial gain

If the publication is distributed under the terms of Article $25 \mathrm{fa}$ of the Dutch Copyright Act, indicated by the "Taverne" license above, 
Review article

\title{
The clinical and prognostic value of motor abnormalities in psychosis, and the importance of instrumental assessment
}

\author{
Peter N. van Harten ${ }^{\mathrm{a}, \mathrm{b}}$, , Sebastian Walther ${ }^{\mathrm{c}}$, Jerillyn S. Kent ${ }^{\mathrm{d}}$, Scott R. Sponheim ${ }^{\mathrm{d}}$, \\ Vijay A. Mittal ${ }^{\mathrm{e}}$ \\ ${ }^{a}$ Department of Psychiatry and Psychology, Maastricht University Medical Centre, Maastricht, The Netherlands \\ b Psychiatric Centre GGz Central, Amersfoort, The Netherlands \\ c Translational Research Center, University Hospital of Psychiatry, University of Bern, Switzerland \\ ' Minneapolis VA Health Care System, USA \\ e Northwestern University, Department of Psychology, Department of Psychiatry, Institute for Policy Research, Department of Medical Social Sciences, Evanston/Chicago, \\ USA
}

\section{A R T I C L E I N F O}

\section{Keywords:}

Instrumental assessment

Motor abnormalities

Movement disorders

Psychosis

Ultra high risk for psychosis

Epidemiology

Prognosis

\begin{abstract}
A B S T R A C T
Motor abnormalities comprise several clinical signs intrinsic to psychosis. Critically, these features are of prognostic value in individuals at-risk for psychosis, and for those in early stages of psychotic disorders. Motor abnormalities such as tremor, rigidity, and neurological soft signs often go unrecognized. Currently, advances in this area are limited by a paucity of theoretical conceptions categorizing or linking these behaviours to underlying neurobiology affected in psychosis. However, emerging technological advances have significantly improved the ability to detect and assess motor abnormalities with objective instruments in a timely and reliable manner. Further, converging evidence has laid the groundwork for theoretically and empirically derived categorization and conceptualization. This review summarizes these advances, stressing the importance of motor abnormalities for understanding vulnerability across different stages of psychosis and introducing these innovative instrumental approaches. Patients, researchers and clinicians will benefit from these new developments, as better assessment aids the development of targeted interventions to ultimately improve the care for individuals experiencing psychosis.
\end{abstract}

\section{Introduction}

Motor abnormalities have been observed in chronic patients with schizophrenia, antipsychotic naïve patients in their first episode, individuals identified as at ultra high-risk (UHR) for psychosis, unaffected first-degree relatives of schizophrenia patients, schizotypal patients, and relatively healthy individuals with verbal auditory hallucinations. The predictive value of motor symptoms for the development and course of psychosis, (Cuesta et al., 2014; Mittal et al., 2008a) as well as what is known of the functional neuroanatomy of motor abnormalities, suggests that these features are an integral part of psychotic psychopathology (Fervaha et al., 2014).

Current diagnostic systems predominantly use mental, cognitive, and affective symptoms to characterize psychotic disorders. Yet, the reliability and accuracy of these traditional diagnostic techniques have been called into question because of factors such as observer bias as well as the confounding influence of particular clinical features such as suspiciousness, cognitive deficits and amotivation. Further, the current diagnostic system weighs positive symptoms heavily, but de-emphasizes critical cognitive and negative symptoms categories, which may be more closely tied to the underlying pathophysiology of psychosis. In this context, it is important to consider that growing evidence indicates that motor abnormalities may make up an objectively measureable symptom dimension of psychosis. Importantly, motor abnormalities can be quantified with innovative instruments, yielding sensitive, valid and reliable data. Also, portable devices allow for continuous monitoring of motor abnormalities outside the clinic and enable the examination of how motor abnormalities may predict aspects of everyday functioning.

In this review we provide a comprehensive primer on motor abnormalities in psychosis (see Table 1 and Fig. 1), discuss related diagnostic, prognostic and treatment value, and describe relationships with cognitive and affective symptoms observed in psychotic disorders. We also discuss new technical developments in the assessment of motor function and future directions in the study of motor abnormalities across a spectrum of psychotic disorders.

\footnotetext{
* Corresponding author at: Utrechtseweg 266, 3818EW, Amersfoort, The Netherlands.

E-mail address: pnvanharten@gmail.com (P.N. van Harten).
} 
Table 1

Definitions (including some comments) of motor abnormalities studied in psychosis.

\begin{tabular}{lll}
\hline $\begin{array}{l}\text { Motor Abnormality } \\
\text { Category }\end{array}$ & $\begin{array}{l}\text { Motor } \\
\text { Abnormality }\end{array}$ & Definition \\
\hline Hyperkinetic & Dyskinesia & $\begin{array}{l}\text { Involuntary movements most } \\
\text { commonly seen in the limbs, mouth, } \\
\text { or tongue resembling either chorea } \\
\text { (i.e., flinging, jerking) or athetosis } \\
\text { (i.e., writhing) (Mittal et al., 2011a; } \\
\text { Mittal et al., 2010b; Pappa and }\end{array}$ \\
& Dazzan, 2009) (see Figs. 1C and 3B-1).
\end{tabular}

Tremor

Catatonia

Involuntary movement that is rhythmic and oscillatory(Deuschl et al., 1998) (see Fig. 1B).

Marked psychomotor disturbance characterized by at least 3 of the following symptoms: stupor, catalepsy, waxy flexibility, mutism, negativism, posturing, mannerism, stereotypy, agitation, grimacing, echolalia, echopraxia(Association, 2013) (hyperkinetic catatonia symptoms are discussed at right).

Increased resistance in response to passive movement about a joint when relaxed(Deuschl et al., 1998); stiffness (Caligiuri et al., 1993) (see Fig. 1B).
Comments

- Historically, both spontaneous and antipsychotic medication induced (i.e., tardive) dyskinesia have been measured via rating scales (e.g., AIMS, DISCUS) developed to assess for tardive dyskinesia, wherein observers code for the presence and severity of dyskinetic movement (e.g., slow, irregular movement of wrists, hands, or fingers; puckering; lip smacking)(Guy, 1976; Kalachnik and Sprague, 1993).

- Instrumental measures sensitive to more subtle manifestations of dyskinesia have been developed and successfully implemented (for example see Fig. 3B-2). These more subtle manifestations of dyskinesia have been assessed during voluntary movement tasks and include force variability secondary to irregular muscle contractions (Caligiuri et al., 1997; Cortese et al., 2005; Mittal et al. 2011a) and dysfluent movement secondary to discoordinated muscle activity (Caligiuri et al., 2010; Teulings et al., 1997).

- In the motor abnormalities in literature about schizophrenia, tremor is described and conceptualized as one of several parkinsonian symptoms (see below for hypokinetic parkinsonian symptoms rigidity and bradykinesia) (Pappa and Dazzan, 2009).

- Tremor is a component of rating scales assessing extrapyramidal side effects (e.g., SAS (Simpson and Angus, 1970)) and Parkinsonism (e.g., UPDRS(Fahn et al., 1987)).

- Instrumental assessments of tremor have been developed wherein individuals sustain short periods of constant isometric force and frequencies of the force signal that are of interest to tremor are analysed (e.g., (Caligiuri et al., 1993; Dean et al., 2004; Koning et al., 2011a)).

- Catatonia is a heterogeneous construct(Association, 2013), with a history of inconsistent definitions and with symptoms spanning motor, volitional, and affective domains(Walther and Strik, 2012).

- Of the pure motor signs highlighted by Walther and Strik (Walther and Strik, 2012), those characterized by abnormally increased movement are listed below:

- Posturing (maintaining positions and postures against gravity actively and spontaneously)(Association, 2013)

- Mannerisms (normal actions are caricatured)(Association, 2013)

- Stereotypies (movements that are not goal-directed but are repetitive and abnormally frequent)(Association, 2013)

- Grimacing

- As with tremor (see above), bradykinesia is rated on various clinical rating scales, and is considered a classic parkinsonian symptom.

- Instruments have been developed to measure duration (Caligiuri et al., 1993; Caligiuri et al., 2010) and speed (Caligiuri et al., 2010) of movement (for example see Fig. 3B2).

- Individuals with bradykinesia have diminished ability to increase movement velocity proportionally to increased movement distance (i.e., decreased velocity scaling)(Cortese et al., 2005), potentially secondary to dysfunctional movement velocity programming(Caligiuri et al., 1998). Instruments have been developed that quantify both the speed and size of movements of different sizes in order to compute velocity scaling (e.g., (Caligiuri et al., 1998; Caligiuri et al., 2009; Caligiuri et al., 2006; Dean and Mittal, 2015; Koning et al., 2011a)).

- As with tremor (see above), rigidity is rated on various clinical rating scales, and is considered a classic parkinsonian symptom.

- Instrumental assessment of rigidity has been accomplished through passive displacement, subsequent quantification of the amount of displacement and the force that was required for the displacement, and calculating the relationship between these two variables(Caligiuri and Galasko, 1992; Caligiuri et al., 1993). Given the central nervous system contribution to parkinsonian rigidity specifically (as opposed to simple muscle stiffness)(Webster, 1966), this same procedure is conducted while the contralateral limb is active, and the relationship between displacement and force in this activated condition is compared to that in the passive (continued on next page) 
Table 1 (continued)

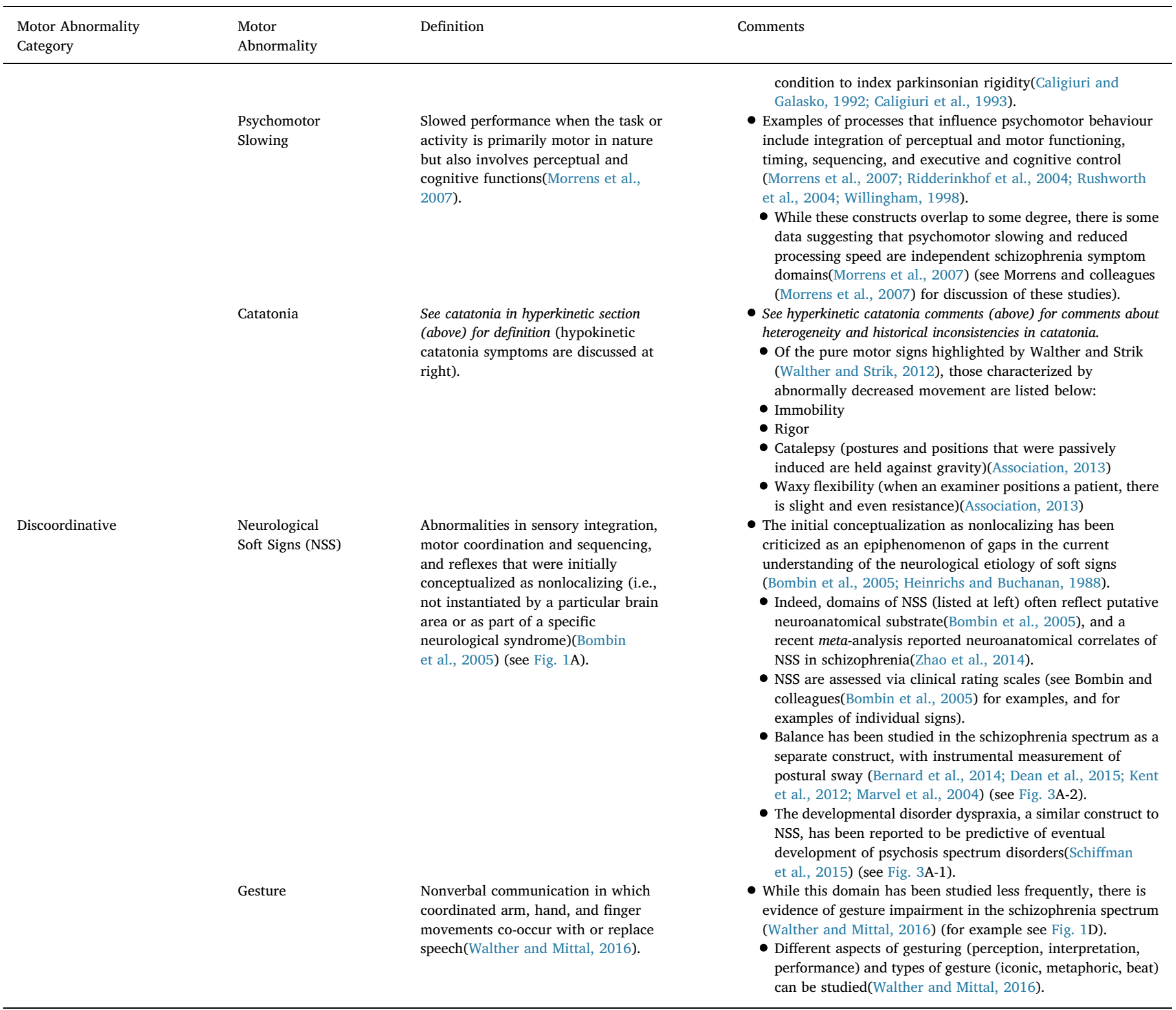

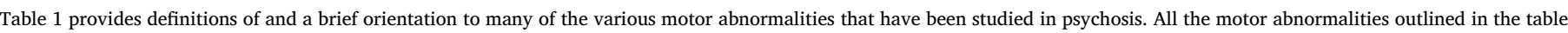

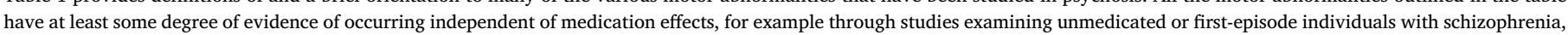

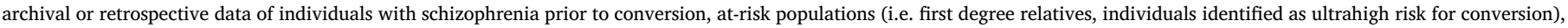

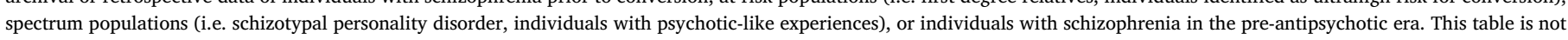

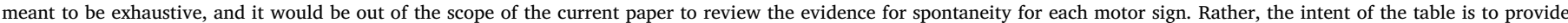

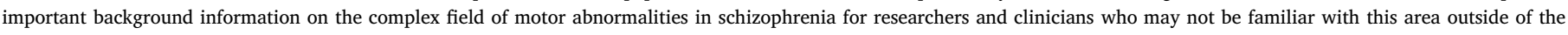

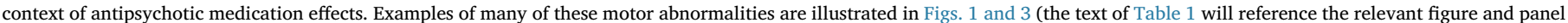
as applicable).

\subsection{Neuroanatomy of motor abnormalities in psychosis}

A substantial proportion of the human brain is devoted to motor control and the generation of behavioural output. The frontal lobe contains a number of premotor areas, such as the cingulate motor area (CMA), supplementary motor area (SMA) and pre-supplementary motor area (pre-SMA), as well as the primary motor cortex (M1). These motor areas are tightly interconnected and further receive input from, and project to, the cerebellum, thalamus and the basal ganglia (see Fig. 2). The basal ganglia include caudate, putamen, internal globus pallidus (GPi), external globus pallidus (GPe) the subthalamic nucleus (STN) and substantia nigra. Several somatotopically organized but functionally segregated cortico-subcortical loops connect the basal ganglia with frontal cortical areas (Obeso et al., 2014). Important motor loops additionally connect the basal ganglia with the cerebellum (Bostan et al., 2010). The cortico-subcortical loops are organized in motor, associative (cognitive), and limbic (emotional) domains, contributing to controlling movement, cognition, reward and emotions. Even though these loops are segregated, information is shared between the loops, and in the event that one of these circuits becomes dysfunctional each of these domains may become disturbed. Thus, predominantly motor disorders such as Parkinson's and Huntington's disease may also include mental and cognitive symptoms and predominantly psychiatric disorders such as psychotic disorders also have motor disturbances (Obeso et al., 2014).

Psychotic disorders are associated with both structural and 

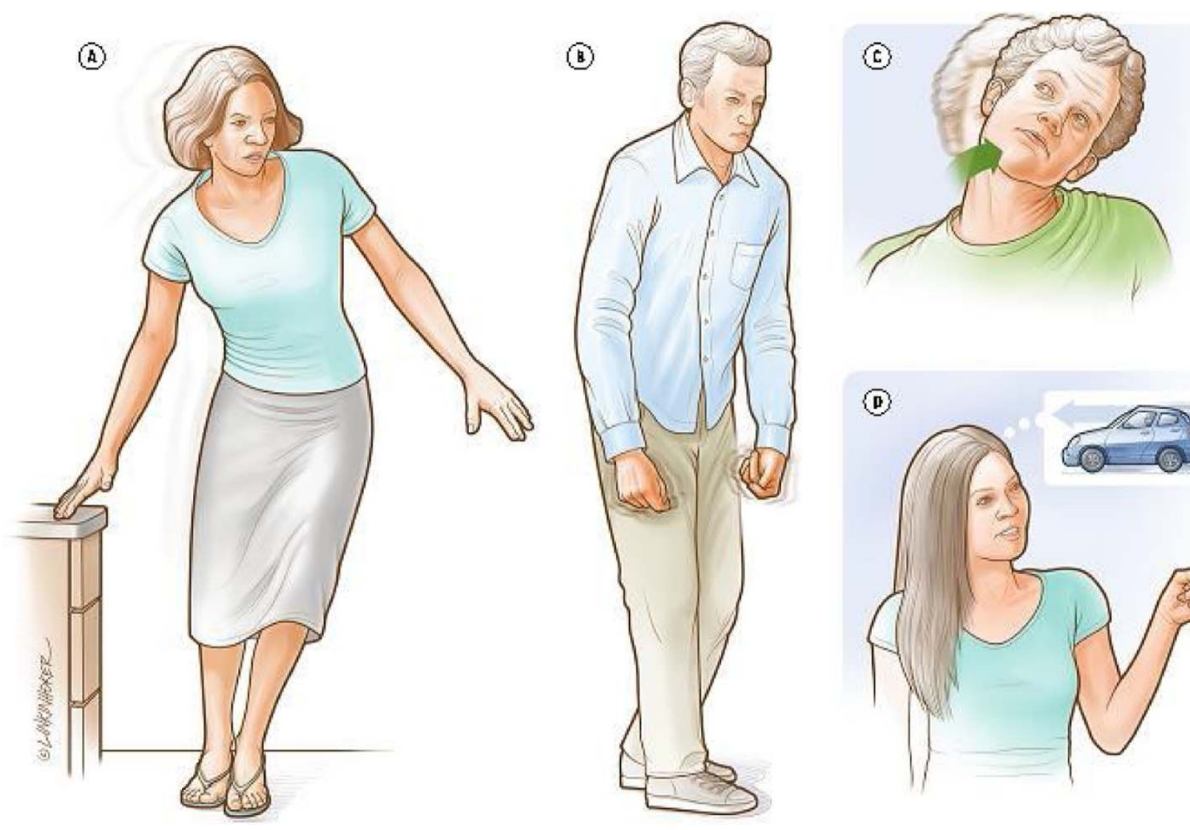

Fig. 1. Illustrations of Motor Abnormalities Common in Psychosis.

A. The female in this illustration is depicting issues with balance. $\boldsymbol{B}$. The male in this figure is showing motor signs consistent with Parkinsonism including rigidity in the trunk, shuffling gait, and tremor in the hands. $C$. The adolescent male is exhibiting torticollis, which is defined by asymmetrical/abnormal head/neck beyond the normal position. This can occur in a jerking/involuntary manner, as depicted in the illustration, or develop slowly and remain in a fixed position. $\boldsymbol{D}$. The adult female in this panel is

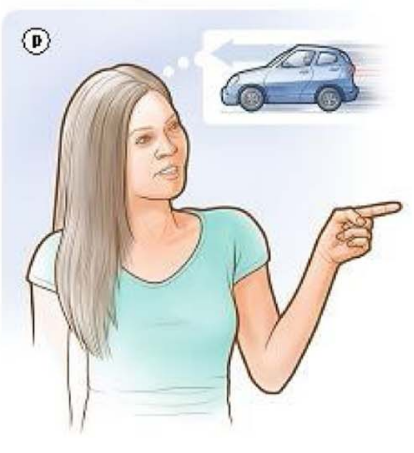
illustrating a gesture-speech mismatch, which occurs when the semantic content of the spoken message is misaligned with the gesture. In this case, the individual is pointing in one direction, to describe a car traveling in the opposite direction.
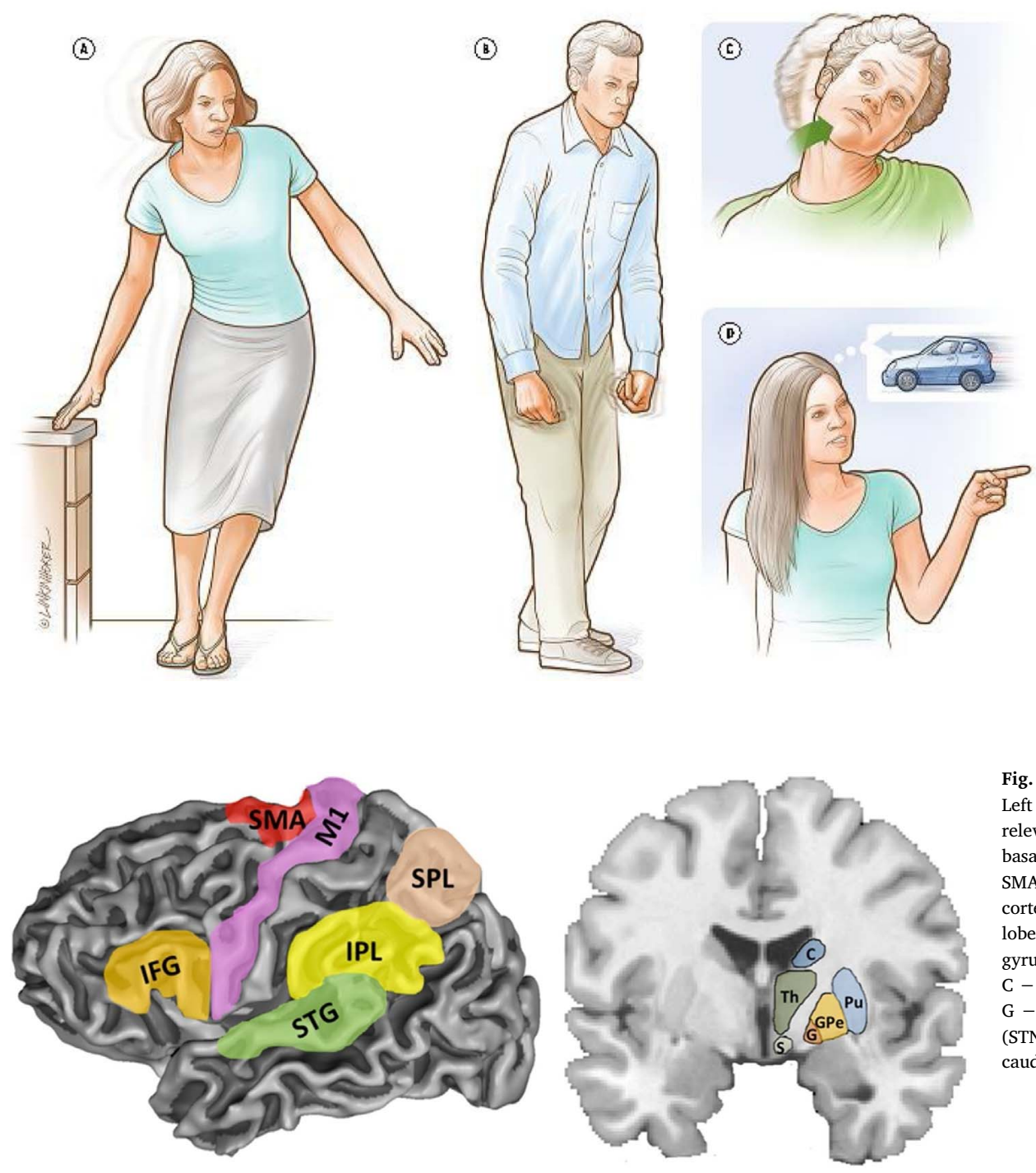

Fig. 2. Brain motor areas.

Left panel: sagittal view on cortical surface with brain areas relevant for gesture processing. Right panel: coronal view on basal ganglia circuitry.

SMA - supplementary motor area, M1-primary motor cortex, SPL - superior parietal lobe, IPL - inferior parietal lobe, IFG - inferior frontal gyrus, STG - superior temporal gyrus.

$\mathrm{C}$ - caudate, $\mathrm{Pu}$ - putamen, $\mathrm{GPe}$ - external globus pallidus, G - internal globus pallidus (GPi), S - subthalamic nucleus (STN), Th - thalamus. Please note that striatum includes caudate and putamen. 
functional alterations of the cerebral motor system, including aberrant white matter microstructure in motor tracts, as well as abnormalities in the shape, size, perfusion patterns, and functional activation of the basal ganglia. Some of these alterations are linked to motor abnormalities (for review see (Hirjak et al., 2015; Walther, 2015; Walther and Strik, 2012)). But currently it is unclear whether the pathophysiology of motor abnormalities in psychoses is shared with similar phenomena noted in primary movement disorders, such as Parkinson's with dopamine (DA) dysfunction in the substantia nigra and putamen or Huntington's disease with abnormal DA activity in the striatum. The neuroimaging literature on motor abnormalities in psychosis is still evolving, but there has been initial mapping of motor signs onto neural structures and function. Dyskinesia is one of the more frequent motor abnormalities in psychosis and is thought to arise from errant striatopallidal activity disinhibiting thalamocortical projections (Obeso et al., 2014). Spontaneous dyskinesia (i.e., dyskinesia that occurs as a function of pathophysiology, and not medication side-effects) has been related to reduced volumes of the putamen in individuals at risk (Mittal et al., 2010a; Mittal et al., 2013), while altered white matter properties have been noted proximal to the basal ganglia in individuals with tardive dyskinesia (Bai et al., 2009). Tourette's syndrome may share abnormal movements, stereotypies and echopraxia with catatonia in psychotic patients and is thought to result from aberrant network activity in multiple cortico-basal ganglia loops (Obeso et al., 2014). Catatonia includes multiple signs such as primary motor (hyperkinetic or hypokinetic) and volitional (e.g. negativism, automatic obedience) abnormalities. fMRI studies have revealed reduced activation in catatonic patients during finger tapping tasks in SMA and M1(Walther, 2015), and a current catatonic state has been associated with relative hyperperfusion of the SMA, particularly in retarded catatonia (Walther et al., 2016a, 2016b). No study has reported on cerebral correlates of parkinsonism in psychosis (Walther, 2015). Finally, neurological soft signs have been linked to reduced fMRI activation in inferior frontal gyrus, putamen and cerebellum, as well as to reduced grey matter volume in SMA, parietal cortex, thalamus, and cerebellum (Hirjak et al., 2015; Walther, 2015; Zhao et al., 2014). It is also important to note that during nonverbal communication the motor system is involved when processing gestures (Stegmayer et al., 2016a; Walther and Mittal, 2016). Relevant brain areas to receptive communication include SMA, M1, parietal areas serving spatial processing and language related areas devoted to semantic processing such as inferior frontal gyrus and superior temporal gyrus (see Fig. 2).

\subsection{The relevance of motor abnormalities to psychotic symptomatology}

Psychotic disorders and schizotypal personality disorder in the Diagnostic and Statistical Manual - Fifth Edition (DSM-5) classification system are characterized by positive, negative, and cognitive symptoms and also 'grossly disorganized or abnormal motor behaviour' (Association, 2013). The focus of diagnostic interviews is typically on hallucinations, delusions, disorganized thought processes and the role of mood states, but less on motor symptoms (Kay et al., 1987; Leucht et al., 2005). This is despite investigations of motor abnormalities in antipsychotic naïve individuals with varying levels of psychotic symptomatology that provide evidence for (i) an association between motor abnormalities and other psychotic symptomatology, (ii) the strengthening of the association with progression toward disorder onset, and (iii) that motor abnormalities predict social and role functional (i.e. occupational) impairment later in the disorder. Specifically, associations between motor abnormalities and clinical and cognitive symptoms have been found in antipsychotic naïve patients in their first episode of psychosis and in UHR individuals (Cortese et al., 2005; Koning et al., 2011b, 2011c; Koning et al., 2010; Mittal et al., 2008b). The correlation has also been found in patients with schizotypy, siblings of patients with schizophrenia, in relatively healthy participants with verbal auditory hallucinations, in the general population (a correlation was found between psychotic like experiences and motor abnormalities) and in healthy children from the general population (a correlation was found between motor abnormalities and psychosis proneness) (Kindler et al., 2016; Koning et al., 2011b, 2011c; Mittal et al., 2011a). Secondly, work with UHR individuals has revealed that the magnitude of the association between motor abnormalities and prodromal symptoms increases over time (Mittal et al., 2008b).

Thirdly, the predictive value of motor abnormalities has been studied in antipsychotic naïve patients in their first episode of psychosis. For example, the incidence of spontaneous Parkinsonism at baseline has been observed to predict cognitive impairment and neurological soft signs 6 months later in psychosis, and further, greater severity of parkinsonism has been found to be related to higher cognitive impairment (Cuesta et al., 2014). Correct expression of hand gestures was found to predict functional outcome and negative symptoms in schizophrenia, with poorer performance indicating inferior outcome(Walther et al., 2016a). Also, in an UHR population, motor abnormalities were related to poor functioning at a cross sectional and longitudinal level and motor abnormalities at baseline predicted conversion to psychosis (Cortese et al., 2005; Mittal et al., 2011b). This predictive value of motor abnormalities stresses the clinical relevance of motor abnormalities as a core manifestation of psychotic spectrum disorders and of vulnerability to psychosis. Therefore, assessment of motor abnormalities, as part of the diagnostic process of psychotic disorders, is essential (Kendler, 2016).

\subsection{Longitudinal outcome of early (childhood) and prodromal motor symptoms}

Motor signs may very well be the first observable symptom of vulnerability for psychotic disorders. Fish (Fish, 1987) proposed that pandysmaturation (disorganized motor and sensory development) reflects psychosis vulnerability in the first 2 years of life. This notion has been widely supported by archival research designs of infants and young children who later develop schizophrenia as adults, revealing a pattern of non-specific motor perturbations (Cannon et al., 2002; Fish, 1987; Marcus et al., 1985), abnormalities in coordination and dyspraxia (Schiffman et al., 2015) and delays in milestones such as smiling, lifting head, sitting, crawling, standing walking and potty-training (Isohanni et al., 2004; Sorensen et al., 2010). A landmark series of innovative studies focusing on the infant and childhood home-movies of adulthood schizophrenia patients observed many of these noted deficits, as well as evidence for signs of more specific striatal-related motor dysfunction such as choreoathetoid movements and posturing of the upper limbs (Walker, 1994). In one of the only studies of its kind, these same investigators found childhood motor abnormalities were also linked to adult ventricular enlargement (Walker et al., 1996).

Some research nonetheless suggests that after age two, specific and diffuse motor signs are no longer distinguishable from control cases (e.g., infancy/childhood videotapes of unaffected siblings or community controls) (Walker et al., 1994). One possible reason is that the abnormalities are more easily detected as motor skills are in peak ascendance (Walker et al., 1994). The field is currently limited by inherent drawbacks of retrospective designs that make it difficult to detail the developmental course of motor abnormalities. For example, other archival designs examining early video-data indicate poor general motor skill development but not involuntary movements such as dyskinesias in older male children age 11-13 (Schiffman et al., 2004). It is clear that the precise pattern of early motor dysfunction development remains unknown.

The broader literature suggests that several factors affect the predictive value of motor signs in this childhood stage. First, studies have shown that motor development aberrations more strongly predict later psychosis when the child has a parent with a psychotic disorder than when the parents are healthy (Erlenmeyer-Kimling et al., 2000; Rosso et al., 2000; Schiffman et al., 2004). This is a critical point: abnormal 
motor behaviours in young children in the general population are not a good predictive marker of schizophrenia, as many children will show these signs and fail to develop psychosis, and many individuals with psychosis will not have histories of these behaviours. The predictive utility appears to be limited to populations at risk (i.e., genetic risk or prodromal syndrome) for developing psychosis. Second, the type of motor behaviour seems to be important. For example, Rosso and Colleagues (Rosso et al., 2000) examined a large birth-cohort sample (including adults with schizophrenia, unaffected siblings, and non-psychiatric controls), and observed that deviance in motor coordination measured at seven years predicted both schizophrenia and unaffected sibling status (indicating a co-familial and perhaps genetic vulnerability), but also noted that unusual movements at ages four and seven predicted the adult schizophrenia status alone (indicating that these movements may be tied uniquely to pathophysiology). There is also evidence that sex differences may play a role in predictive utility. Specifically, a study evaluating early motor behaviours in a Danish high-risk cohort (following offspring of a parent with schizophrenia from childhood through adulthood) determined that general neuromotor functioning among boys alone (e.g., difficulty manipulating silverware, observed during a videotaped lunch period) predicted later onset of schizophrenia in adulthood (Schiffman et al., 2004). However, more work, aimed at mechanism, is sorely needed to examine this interesting direction. Further, it is also possible that the motor signs remain predictive across early development, but our current strategies for assessing early stages are not sufficiently sensitive to capture subtleties of early development. While one solution is to employ new instrumental measures at these earlier periods in prospective studies, another strategy is to target broader and more proximal indices of motor skills. For example, performance in curricula requiring proficient motor skills shows promise as a predictive variable (Isohanni et al., 2004).

The predictive value of motor signs appears to take on increased significance during the adolescent period, particularly in youth meeting criteria for a high-risk/prodromal syndrome. Perhaps the predictive value is stronger because it is during this period that the DA abnormalities characteristic of psychosis appear to become significant (Egerton et al., 2013); it is possible that because the DA activity in the same basal ganglia circuits also governs motor activity, observable aberrations in motor behaviour (e.g., spontaneous dyskinesia) represent sensitive prognostic indicators (Mittal et al., 2010a). Indeed, research in this period suggests that spontaneous dyskinesias are closely tied to striatal volume decrease (Mittal et al., 2010b) and symptoms. (Kindler et al., 2016; Mittal et al., 2007a) Further, the presence of these motor signs predicts conversion to psychosis within a narrow 2-year window (Callaway et al., 2014; Mittal and Walker, 2007). Other motor abnormalities also appear to be relevant in this population. For example, recent findings suggest that sensorimotor integration deficits are tied to aberrant cerebellar white matter-track development and progressive negative symptoms over a one year period (Mittal et al., 2014), and both deficits in motor learning and postural sway (both tied to the cerebellum as well) are linked to the longitudinal increase in negative symptoms (Bernard et al., 2014; Dean et al., 2014; Dean and Mittal, 2015). This series of findings is exciting as it speaks to broad prognostic value (with significant translational potential) as well as the promise for distinct motor behaviours to speak to unique subtypes of psychosis. It also reaffirms the assertion that motor abnormalities appear to be a function of pathophysiology in psychotic disorders, and not exclusively a medication side effect.

\subsection{Instrumental assessment of motor abnormalities}

In contrast to other psychotic symptoms, motor abnormalities are visible to trained clinicians. This offers the possibility of alternative assessment techniques. In clinical practice a systematic evaluation of motor abnormalities is recommended. Assessments in both clinical and research settings have historically used clinical examination and various rating scales. Common rating scales are summarized in the supplementary material Table 1 . However, rating scales are prone to observer bias and are not designed to detect subclinical motor abnormalities. Further, to be accurately used intensive rater training is required.

Video recordings have allowed for improved interrater reliability, but do not remove the potential for inconsistencies and errors.

Several instruments have recently been developed for measuring various motor abnormalities. Instrumental measurement has great advantages as it lacks observer bias, is highly reliable, very sensitive, may detect subclinical motor abnormalities, and requires little training. In addition, results from instruments are linearly related to severity of the motor abnormality (in contrast with ordinal outcomes of clinical rating scales) and direct data processing is possible. Also portable devices can be developed, allowing long-term real world assessment. In combination with the Experience Sampling Method (ESM) a motor-mentalcognitive real world assessment of psychotic symptoms may be possible (Bakker et al., 2013).

Instrumental measurement has already been used in research settings with various populations such as patients with psychotic disorders (Caligiuri et al., 1997; Walther et al., 2009), individuals at UHR for psychosis (Dean and Mittal, 2015; Mittal et al., 2007b), bipolar disorder (Bolbecker et al., 2011), schizotypal personality disorder (Neumann and Walker, 2003), siblings of patients with schizophrenia (Koning et al., 2011b), healthy individuals hearing voices (Willems et al., 2016), and healthy individuals taking $2 \mathrm{mg}$ of haloperidol (Logemann et al., 2017). Table 2 lists several instruments used to measure various motor abnormalities. With accelerometers and gyroscopes integrated into smartphones, mobile applications that measure motor abnormalities have already been developed (e.g., assessment of tremor). With available pressure-sensitive displays, applications that can measure other motor abnormalities such as dyskinesia will be developed in the near future.

As noted, instrumental measures are highly sensitive, and can detect the same abnormalities that would be identified using traditional observer-based methods, as well as subthreshold abnormalities that might

Table 2

Instruments that are used to measure some common motor abnormalities.

\begin{tabular}{|c|c|c|}
\hline Instrument & Motor abnormality measured & Comments \\
\hline Force variability & Dyskinesia & Tested on reliability and validity(Caligiuri et al., 1997) \\
\hline Handwriting kinematics & Dyskinesia & Figure B2 \\
\hline $\begin{array}{l}\text { Several apps, 'StudyMyTremor' } \\
\text { 'LiftPulse' }\end{array}$ & Tremor & $\begin{array}{l}\text { Use accelerometers embedded in smartphones. Quantify frequency and amplitude of tremor(Senova } \\
\text { et al., 2015) }\end{array}$ \\
\hline Inertial sensors & Bradykinesia & Tested on reliability and validity(Mentzel et al., 2016a; Mentzel et al., 2016b) \\
\hline Balance & Neurological Soft Signs & Figure A2 \\
\hline Glove & Gestures & $\begin{array}{l}\text { Used in combination with virtual reality environment to improve joint attention in patients with } \\
\text { pervasive developmental disorder. (Cheng and Huang, 2012; Walther and Mittal, 2016) }\end{array}$ \\
\hline Actigraphy & $\begin{array}{l}\text { Total activity counts, } \\
\text { Restlessness }\end{array}$ & $\begin{array}{l}\text { Tested on reliability and validity; can be used to measure (i)daily activity/restlessness, (ii) } \\
\text { antipsychotic-induced akathisia, (iii) restless legs syndrome. (Janno et al., 2008; Tuisku et al., 2005; } \\
\text { Tuisku et al., 2004; Walther et al., 2009) }\end{array}$ \\
\hline
\end{tabular}



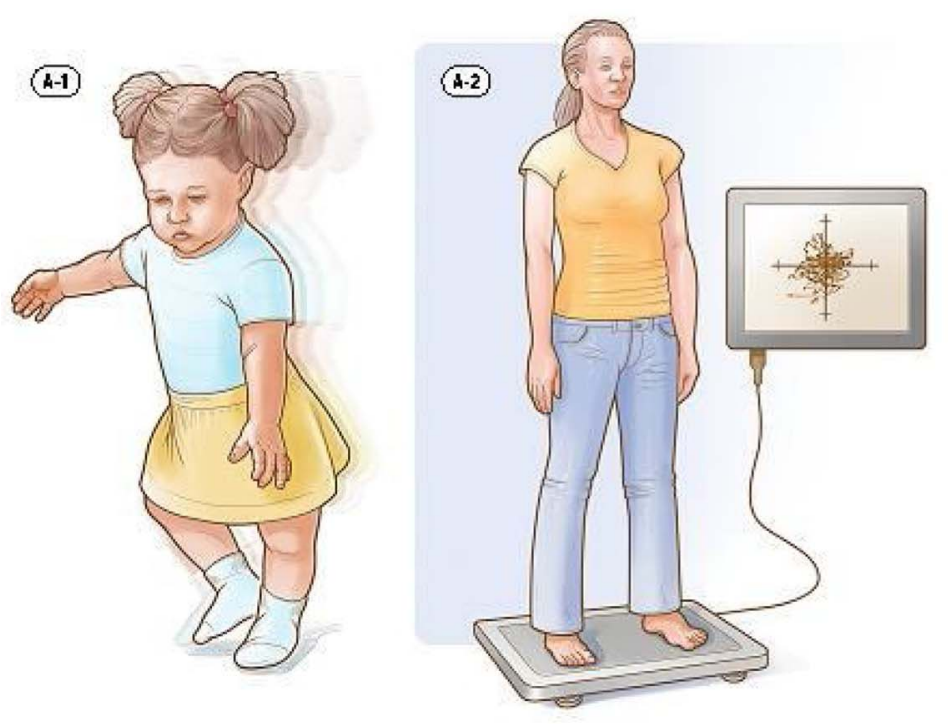

Fig. 3. Practical Applications for Instrumental Motor Approaches. Panel $\boldsymbol{A}$-1 depicts clumsiness and issues with posture (Walker et al., 1994), which are assessed later in development with a sensitive digital scale (A-2) (Bernard et al., 2014). Panel B-1 illustrates an athetoidic withering of the left hand (Walker et al., 1994). B-2 illustrates an instrumental approach using a handwriting kinematics task that is designed to tap into the same brain circuit vulnerability (Dean et al., 2013).
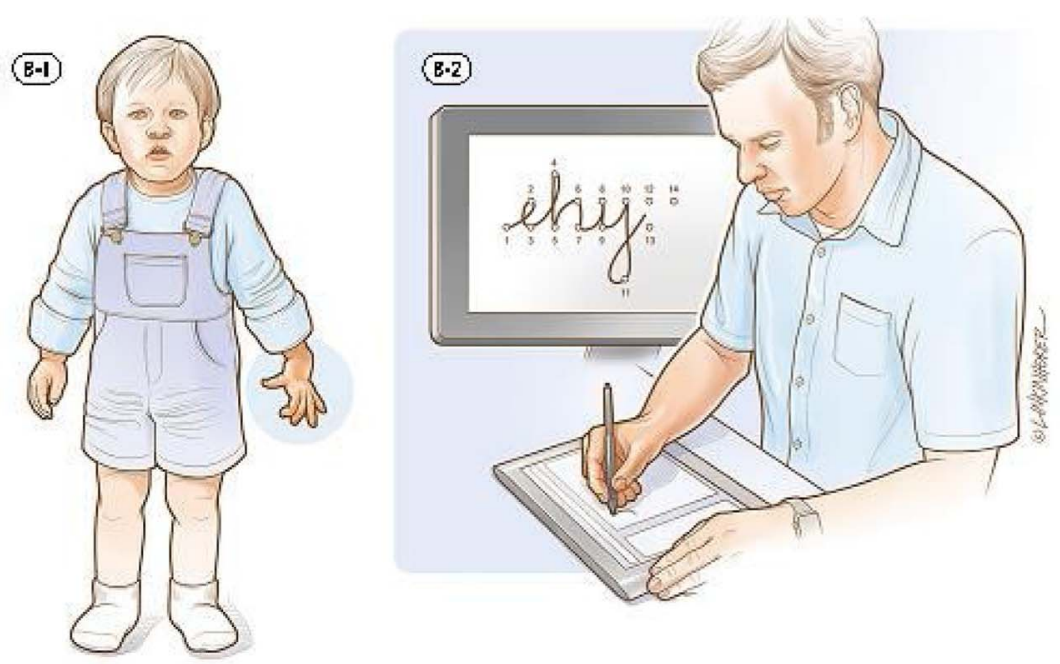

be missed by trained raters (Cortese et al., 2005). Further, instrumental measurements are highly useful in tracking development, where the same underlying vulnerability in the motor system may present differently at different stages. For example, clumsiness (Fig. 3: A-1) is more easily identifiable while motor skills are in ascendance, and can be more difficult to distinguish in later developmental periods. However, the same underlying cerebellar vulnerability remains present, and the more subtle related motor behaviours such as postural sway can be detected with sensitive instrumental balance scales (Fig. 3: A-2). Similarly, some research suggests that athetoidic movements, reflective of vulnerable striatal circuit, are present in young children who later develop schizophrenia as adults (Fig. 3: B-1), but in later childhood, this type of behaviour is no longer detectable (Walker et al., 1994). However, the innervated striatal system remains present, and instrumental approaches, such as handwriting kinematics, focusing on related motor variables (Fig. 3 B-2) can tap into the same vulnerability (Dean and Mittal, 2015; Dean et al., 2013).

\section{Innovations in motor assessment}

Despite much advancement there remain outstanding questions about motor abnormalities in psychosis, as well as future directions to be explored. Panel 1 outlines a few examples of critical questions and controversies in the field, and future directions are discussed below.

\subsection{Mental-cognitive-motor network}

The network approach is built on the idea that psychopathology can be perceived as the interaction of affective, cognitive, and behavioural components that form, together with personal and environmental risk factors, a dynamic psychometric framework (Isvoranu et al., 2016). There are several reasons to add motor abnormalities as one of the components in the network approach. As reviewed above, motor abnormalities have a predictive value, correlate with mental and cognitive symptoms and can be measured instrumentally. Also, neuroimaging studies have demonstrated that some of the motor abnormalities reported in psychosis stem from structural and functional impairments within the cerebral motor system (Walther, 2015; Walther and Strik, 2012). For example, neurological soft signs and gesture abnormalities may be related to aberrant integration of motor and sensory information (Mittal et al., 2014; Stegmayer et al., 2016a; Zhao et al., 2014). It could be that delayed or imperfect network maturation is responsible for motor abnormalities in psychosis. If so, longitudinal studies in adolescents at risk may demonstrate this link. Such studies should include the simultaneous measurement of motor behaviour (with wearable devices during the day) and psychiatric symptoms (e.g., with ESM). This will yield insight into the sequence of symptoms, possible etiologic factors, and the role of motor abnormalities in the progression from prodrome to psychosis (Bakker et al., 2013). 


\subsection{New targets for instrumentation and intervention}

In the neurodevelopmental theory of psychotic disorders, abnormal brain development is considered to be a contributing factor to the disorder. The following motor phenomena have been related to the risk of psychotic disorders later in life (Khandaker et al., 2014) and are amenable to instrumental assessment.

\subsubsection{Gesture}

Gesture as defined in Table 1 is linked with language and cognitive systems and, similar to dyskinesia and bradykinesia, gesture abnormalities have been found in all stages of the psychotic disorder (prodromal, antipsychotic naive and chronic psychosis populations) (Millman et al., 2014; Stegmayer et al., 2016b; Walther and Mittal, 2016). Gestures are part of non-verbal communication and patients with psychosis spectrum disorders often show poor social interaction, which can be hampered by abnormalities of gesture perception, interpretation, and performance (Walther et al., 2015). Compared to healthy controls, patients with schizophrenia or with schizotypal personality disorder exhibit hand gestures less frequently, (Lavelle et al., 2013; Mittal et al., 2006; Walther and Mittal, 2016) and UHR individuals show more mismatch (semantic incongruency between the content of speech and a given gesture (see Fig. 3,1b)), and retrieval (used during pauses in speech while a person appears to be searching for a word or idea) problems than controls (Bernard et al., 2015; Millman et al., 2014 Millman et al., 2014). Impaired gesture performance is closely linked to overall nonverbal communication skills in schizophrenia (Walther et al., 2015), specific hypokinetic or hyperkinetic motor abnormalities (Walther et al., 2013), negative symptoms (Lavelle et al., 2013; Millman et al., 2014; Walther et al., 2015; Walther et al., 2013), and grey matter reduction (Stegmayer et al., 2016a) and is predictive of poor functional outcome over six months (Walther et al., 2016a). Furthermore, cultural differences have to be considered when studying gesture, particularly cultural impact on gesture content and frequency. All these findings stress the need for objective instrumental measurement of gestures, and this may be possible with an innovative wearable kinesthetic glove using knitted piezoresistive fabric (KPF) sensor technology. This glove has the capacity to capture hand movement and gestures and has three KPF goniometers, which are able to track flexion and extension of the metacarpophalangeal joint (i.e. lowest and largest knuckle) of the thumb, index, and middle fingers. It has been tested for continuous monitoring of daily-life activities in stroke survivors (Carbonaro et al., 2014). In psychosis, this technique will permit disentangling poor gesture planning from impaired action control because of improved assessment of temporo-spatial errors of hand gestures. Combined with virtual reality experiments and quantitative analysis of real-life video recordings, the glove will be a powerful tool to study gesture.

\subsubsection{Balance/Coordination}

Several studies suggest that not only basal ganglia but also cerebellar abnormalities contribute to motor abnormalities in the prodromal phase and full clinical disorder, and may also contribute to cognitive disturbances. Increased postural sway is one manifestation of cerebellar dysfunction and has been studied with a sensitive digital scale (shown in Fig. 3A2), which is able to detect subtle postural sway movements. Increased postural sway in the UHR group has been found to predict changes in negative symptoms. Such a link between cerebellar-sensitive behaviour and mental symptoms raises the possibility of a biological marker that is present prior to the onset of psychosis (Bernard et al., 2014; Dean et al., 2014; Dean et al., 2015).

\subsubsection{Neurological soft signs}

Neurological soft signs have been studied intensively in patients with schizophrenia and in early detection of psychosis spectrum disorders including UHR individuals (Chan et al., 2016; Mittal et al., 2014;
Mittal et al., 2007a). However, the sensitivity and specificity of neurological soft signs in the psychosis continuum is still controversial. There appears to be no widely accepted means of assessing neurological soft signs with objective instrument-based measurement. An instrument that is able to continuously monitor neurological soft signs would be a marked advance due to the increased precision and sensitivity of time series data that would be provided by this type of measurement.

\subsubsection{Medication side effects}

Medication, in particular psychotropics, is frequently the cause of motor side effects such as tremor, akathisia, bradykinesia, dyskinesia and dystonia. Tremor is one of the most common side effects and can be measured with mobile applications that use the smartphone's accelerometer and gyroscope signals. The signal metrics used to characterize tremor are mainly based on the magnitude of acceleration and rotation rate vectors of the device (Carignan et al., 2015; Kostikis et al., 2015). Akathisia is characterized by subjective inner restlessness and objective motor manifestations such as leg movements. Actigraphy is able to measure the objective component of akathisia (Poyurovsky et al., 2000). Bradykinesia as part of Parkinsonism can be measured with several devices such as inertial sensors as shown in the video. (Mentzel et al., 2016a) Instrumental measurement of dyskinesia, based on force variability, was developed by Caligiuri as early as the nineties (Caligiuri et al., 1997) and employs an easy to use device that is shown in the video (video link here).

\section{Conclusions}

Motor abnormalities are an important component of psychosis spectrum disorders and are highly amenable to objective assessment. Specifically, new electronic and software-based instruments allow reliable measurement of motor abnormalities. Patients, researchers and clinicians will benefit from these new developments, as better assessment aids the development of targeted interventions to ultimately improve the care for individuals experiencing psychosis. The next steps in investigating motor abnormalities require better models of motor abnormalities, common definitions of abnormal motor behaviours, and large-scale longitudinal measurements.

\section{Author's contribution}

All five authors state:

Substantial contribution in writing the article.

Revising it critically for important intellectual content.

Final approval.

Agree to be accountable for all aspects of the work in ensuring that questions related to the accuracy or integrity of any part of the work are appropriately investigated and resolved.

\section{Role of funding source}

None.

\section{Conflict of interest}

None of the authors have a conflict of interest concerning this paper.

\section{Controversies and critical questions}

Even though the association between motor abnormalities and psychosis has been increasingly studied and repeatedly demonstrated, there are some issues with motor abnormalities in the psychosis spectrum that remain poorly understood. A few examples of controversy are given below.

1. There is little data on the longitudinal progression of spontaneous movement abnormalities and how these abnormalities are influenced 
by antipsychotic medication. One study suggests very heterogeneous courses, i.e. some patients experiencing deterioration, some improvement while in others motor abnormalities remain unaffected by antipsychotics (Peralta and Cuesta, 2010). Much more work on this clinically highly relevant topic is needed.

2. With the current understanding of functional neuroanatomy in the motor system it is hard to explain how hyperkinetic and hypokinetic motor abnormalities may exist in the same individual at the same time. Even though a sequential appearance of different motor abnormalities in one person could be attributed to aberrant network dynamics, the concurrent appearance of bradykinesia and dyskinesia remains mysterious.

3. It has been noted that various motor abnormalities are present across a range of psychological and developmental disorders (see (Bernard and Mittal, 2015a, 2015b) and Walther \& Morrens (Walther and Morrens, 2015) for discussion). While a detailed review of which motor abnormalities are present to what extent in which disorders is out of the scope of the current review, it is notable that there is appreciable overlap, with some motor abnormalities presenting across multiple disorders. For example, neurological soft signs (e.g., Goswami and colleagues(Goswami et al., 2006)), postural control dysfunction (Bolbecker et al., 2011), and instrument-measured dyskinesia and bradykinesia(Lohr and Caligiuri, 2006) have all been reported in individuals with bipolar disorder. Continued work examining these and other motor abnormalities in multiple populations will be necessary to elucidate the significance of common motor abnormalities across disorders (i.e., perhaps the same motor abnormality in multiple disorders reflects a common neural disruption or is associated with a specific transdiagnostic symptom domain).

4. The field would benefit from an integrative model accounting for various motor abnormalities.

\section{Drug induced movement disorders: evaluation}

This examination for drug induced movement disorders takes 3-5 min. Therefore, it can easily be integrated into everyday clinical practice. Ask your patient to sit in a chair preferable without armrests, and explain that some medicines can cause movement disorders and that a short evaluation can establish if that is the case.

\section{Anamnesis}

General

a) Do you have anything in your mouth (e.g., candy)? If so, please remove it.

b) Are you currently having any problems with your teeth or dentures?

c) How do you tolerate the medicine? Have you experienced any side effects?

d) Have you experienced movements over which you have no control? Did this happen before? Did it occur after you started taking the medicine?

\section{Dyskinesia/dystonia}

a) Have you noticed that the muscles around your mouth, lips, jaw or tongue sometimes move on their own without your wanting them to? Do any other muscles move of their own accord, for example your hands/fingers, feet/toes, neck, face, eyelids?

b) Have you noticed muscles spasm sometimes? Did your head tilt to the side? Did your eyes close involuntary? Did your eyes turn up involuntary or anything similar?

c) Do you have problems eating, swallowing, talking, writing, walking, getting dressed, hygiene or anything similar? Do the involuntary movements cause it?

\section{Parkinsonism}

a) Are you slower than usual? Are movements more difficult, do you feel stiff?

b) Has your voice changed, less understandable, less loud?

c) Have you noticed that you make more saliva? Does it bother you?

d) Do you sometimes have problems with trembling (demonstrate resting tremor of the hand)?

e) Has your handwriting changed since you have been taking medicines?

\section{Akathisia}

Do you feel restless, particularly in your legs? Is it difficult for you to sit still? Do you tend to keep moving your legs?

\section{Myoclonus}

Explain what myoclonus is. Myoclonus is a brief, sudden jerk caused by muscle contraction. You probably recognize this, for example just before you fall asleep. Do you now experience this more frequently than before you started using medicines?

\section{General}

a) Do the symptoms change over the course of the day? If yes, how?

b) Are there specific situations that provoke, worsen or lessen the movements?

c) Are there any additional noteworthy phenomena (numbness, pain, sensory trick (reduction of dystonic movements by touching the affected or adjacent body parts))?

d) Do the involuntary movements embarrass you?

\section{The examination}

The examination is done with the patient in a sitting position unless otherwise noted.

1) ASK YOUR PATIENT TO SIT RELAXED, WITH HANDS ON THE THIGHS.

Look for: dyskinesia, dystonia, akathisia, poverty of movement, tremor; breathing pattern (irregular? fast?).

2) ASK PATIENT TO SIT BENT OVER WITH ELBOWS ON KNEES AND ARMS HANGING BETWEEN LEGS.

Look for: tremor in the hands.

3) ASK YOUR PATIENT TO DROP HIS/HER ARMS TO THE SIDE.

Look for: dyskinesia or tremor of the hands/fingers/legs/jaw or anywhere else. In the case of dyskinesia of the hands or trunk, also observe the patient's toes.

4) ASK YOUR PATIENT TO STRETCH HIS/HER ARMS STRAIGHT OUT IN FRONT, WITH PALMS FACING DOWN AND FINGERS SLIGHTLY SPREAD OUT.

Look for: postural tremor in the hands. A very slight tremor is often normal.

5) ASK YOUR PATIENT TO PERFORM THE FOLLOWING MOVEMENTS SEVERAL TIMES (LEFT AND RIGHT IN SUCCESSION AND AS FAST AS POSSIBLE).

Look for: poverty of movement and getting fatigued.

a. Open and shut the hand entirely.

b. Make a large scissoring motion between the thumb and index finger.

c. Make a turning movement with the hand as if screwing in a light bulb (as far back and forth).

d. Stamp the heel on the ground, raising the foot about $5 \mathrm{~cm}$.

6) PROVOCATION TEST: DYSKINESIA AROUND THE MOUTH.

Ask the patient to touch the tips of the fingers with the thumb of the same hand as fast as possible. 
Look for: dyskinesia around the mouth.

7) ASK THE PATIENT TO OPEN HIS/HER MOUTH AND EXAMINE THE TONGUE, IF IN DOUBT, PERFORM SAME PROVOCATION TEST. EXAMINE THE TONGUE TWICE.

Look for: turning, worm-like movements, involuntary sticking out of the tongue, sticking the tongue repeatedly in the cheek. Saliva flow? Condition of the teeth? A slight tremor when sticking out the tongue is normal.

8) BEND AND STRETCH YOUR PATIENT'S ARMS AND LEGS AND MOVE HER/HIS HEAD.

Evaluate: stiffness (rigidity), which feels like bending a lead pipe or sometimes like a rhythmic interruption while bending, as with a ratchet.

9) ASK THE PATIENT TO WALK APPROXIMATELY $20 \mathrm{~m}$ (FOR EXAMPLE IN THE HALL), FAR ENOUGH FOR A NORMAL GAIT TO DEVELOP.

Look for: Is standing up difficult? During walking, pay attention to the arm swing, the length of the stride, bent posture, facial expression and the development of or increase in dyskinesia's, dystonia's or tremors (particularly in the hands).

10) PROVOCATIONTEST: AKATHISIA.

Back in the examination room, ask your patient to stand (you stand also).

Look for: the legs (walking in place, repeated contraction of the calf muscles).

11) ASK YOUR PATIENT TO WRITE SOMETHING AND TO DRAW AN ARCHIMEDEAN SPIRAL.

Look for: tremor, micrographia, clumsiness, and writer's cramp. Notice any development of, or increase in dyskinesia or dystonia.

\section{References}

American Psychiatric Association, A.P, 2013. Diagnostic and Statistical Manual of Mental Disorders, fifth edition. American Psychiatric Association, Arlington, VA.

Bai, Y.M., Chou, K.H., Lin, C.P., Chen, I.Y., Li, C.T., Yang, K.C., Chou, Y.H., Su, T.P., 2009. White matter abnormalities in schizophrenia patients with tardive dyskinesia: a diffusion tensor image study. Schizophr. Res. 109, 167-181.

Bakker, P.R., Wichers, M., van Harten, P.N., Myin-Germeys, I., Delespaul, P., van Os, J., 2013. Novel directions for psychiatric diagnosis: from psychopathology to motor function to monitoring technology. Epidemiol. Psychiatric Sci. 22, 289-295.

Bernard, J.A., Mittal, V.A., 2015a. Updating the research domain criteria: the utility of a motor dimension. Psychol. Med. 45, 2685-2689.

Bernard, J.A., Millman, Z.B., Mittal, V.A., 2015b. Beat and metaphoric gestures are differentially associated with regional cerebellar and cortical volumes. Hum. Brain Mapp. 36, 4016-4030.

Bernard, J.A., Dean, D.J., Kent, J.S., Orr, J.M., Pelletier-Baldelli, A., Lunsford-Avery, J.R., Gupta, T., Mittal, V.A., 2014. Cerebellar networks in individuals at ultra high-risk of psychosis: impact on postural sway and symptom severity. Hum. Brain Mapp. 35, 4064-4078.

Bolbecker, A.R., Hong, S.L., Kent, J.S., Klaunig, M.J., O'Donnell, B.F., Hetrick, W.P., 2011. Postural control in bipolar disorder: increased sway area and decreased dynamical complexity. PLoS One 6, e19824.

Bombin, I., Arango, C., Buchanan, R.W., 2005. Significance and meaning of neurological signs in schizophrenia: two decades later. Schizophr. Bull. 31, 962-977.

Bostan, A.C., Dum, R.P., Strick, P.L., 2010. The basal ganglia communicate with the cerebellum. Proc. Natl. Acad. Sci. U. S. A. 107, 8452-8456.

Caligiuri, M.P., Galasko, D.R., 1992. Quantifying drug-induced changes in parkinsonian rigidity using an instrumental measure of activated stiffness. Clin. Neuropharmacol. $15,1-12$.

Caligiuri, M.P., Lohr, J.B., Jeste, D.V., 1993. Parkinsonism in neuroleptic-naive schizophrenic patients. Am. J. Psychiatry 150, 1343-1348.

Caligiuri, M.P., Lohr, J.B., Rotrosen, J., Adler, L., Lavori, P., Edson, R., Tracy, K., 1997 Reliability of an instrumental assessment of tardive dyskinesia: results from VA Cooperative Study \#394. Psychopharmacology (Berl.) 132, 61-66.

Caligiuri, M.P., Lohr, J.B., Ruck, R.K., 1998. Scaling of movement velocity: a measure of neuromotor retardation in individuals with psychopathology. Psychophysiology 35, 431-437.

Caligiuri, M.P., Teulings, H.L., Filoteo, J.V., Song, D., Lohr, J.B., 2006. Quantitative measurement of handwriting in the assessment of drug-induced parkinsonism. Hum. Mov. Sci. 25, 510-522.

Caligiuri, M.P., Teulings, H.L., Dean, C.E., Niculescu, A.B., Lohr, J., 2009. Handwriting movement analyses for monitoring drug-induced motor side effects in schizophrenia patients treated with risperidone. Hum. Mov. Sci. 28, 633-642.
Caligiuri, M.P., Teulings, H.L., Dean, C.E., Niculescu 3rd, A.B., Lohr, J.B., 2010. Handwriting movement kinematics for quantifying extrapyramidal side effects in patients treated with atypical antipsychotics. Psychiatry Res. 177, 77-83.

Callaway, D.A., Perkins, D.O., Woods, S.W., Liu, L., Addington, J., 2014. Movement abnormalities predict transitioning to psychosis in individuals at clinical high risk for psychosis. Schizophr. Res. 159, 263-266.

Cannon, M., Caspi, A., Moffitt, T.E., Harrington, H., Taylor, A., Murray, R.M., Poulton, R., 2002. Evidence for early-childhood, pan-developmental impairment specific to schizophreniform disorder: results from a longitudinal birth cohort. Arch. Gen. Psychiatry 59, 449-456.

Carbonaro, N., Dalle Mura, G., Lorussi, F., Paradiso, R., De Rossi, D., Tognetti, A., 2014 Exploiting wearable goniometer technology for motion sensing gloves. IEEE J. Biomed. Health Inform. 18, 1788-1795.

Carignan, B., Daneault, J.F., Duval, C., 2015. Measuring tremor with a smartphone. Methods Mol. Biol. 1256, 359-374.

Chan, R.C., Xie, W., Geng, F.L., Wang, Y., Lui, S.S., Wang, C.Y., Yu, X., Cheung, E.F., Rosenthal, R., 2016. Clinical utility and lifespan profiling of neurological soft signs in schizophrenia spectrum disorders. Schizophr. Bull. 42, 560-570.

Cheng, Y., Huang, R., 2012. Using virtual reality environment to improve joint attention associated with pervasive developmental disorder. Res. Dev. Disabil. 33, 2141-2152.

Cortese, L., Caligiuri, M.P., Malla, A.K., Manchanda, R., Takhar, J., Haricharan, R., 2005. Relationship of neuromotor disturbances to psychosis symptoms in first-episode neuroleptic-naive schizophrenia patients. Schizophr. Res. 75, 65-75.

Cuesta, M.J., Sanchez-Torres, A.M., de Jalon, E.G., Campos, M.S., Ibanez, B., MorenoIzco, L., Peralta, V., 2014. Spontaneous parkinsonism is associated with cognitive impairment in antipsychotic-naive patients with first-episode psychosis: a 6-month follow-up study. Schizophr. Bull. 40, 1164-1173.

Dean, D.J., Mittal, V.A., 2015. Spontaneous parkinsonisms and striatal impairment in neuroleptic free youth at ultrahigh risk for psychosis. NPJ Schizophr. 1.

Dean, C.E., Russell, J.M., Kuskowski, M.A., Caligiuri, M.P., Nugent, S.M., 2004. Clinical rating scales and instruments: how do they compare in assessing abnormal, involuntary movements. J. Clin. Psychopharmacol. 24, 298-304.

Dean, D.J., Teulings, H.L., Caligiuri, M., Mittal, V.A., 2013. Handwriting analysis indicates spontaneous dyskinesias in neuroleptic naive adolescents at high risk for psychosis. J. Vis. Exp.: JoVE e50852.

Dean, D.J., Bernard, J.A., Orr, J.M., Pelletier-Baldelli, A., Gupta, T., Carol, E.E., Mittal, V.A., 2014. Cerebellar morphology and procedural learning impairment in neuroleptic-Naive youth at ultrahigh risk of psychosis. Clin. Psychol. Sci. 2, 152-164.

Dean, D.J., Kent, J.S., Bernard, J.A., Orr, J.M., Gupta, T., Pelletier-Baldelli, A., Carol, E.E., Mittal, V.A., 2015. Increased postural sway predicts negative symptom progression in youth at ultrahigh risk for psychosis. Schizophr. Res. 162, 86-89.

Deuschl, G., Bain, P., Brin, M., 1998. Consensus statement of the movement disorder society on tremor. ad hoc scientific committee. Mov. Disord. 13 (Suppl. 3), 2-23.

Egerton, A., Chaddock, C.A., Winton-Brown, T.T., Bloomfield, M.A., Bhattacharyya, S., Allen, P., McGuire, P.K., Howes, O.D., 2013. Presynaptic striatal dopamine dysfunction in people at ultra-high risk for psychosis: findings in a second cohort. Biol. Psychiatry 74, 106-112.

Erlenmeyer-Kimling, L., Rock, D., Roberts, S.A., Janal, M., Kestenbaum, C., Cornblatt, B., Adamo, U.H., Gottesman, I.I., 2000. Attention, memory, and motor skills as childhood predictors of schizophrenia-related psychoses: the New York High-Risk Project. Am. J. Psychiatry 157, 1416-1422.

Fahn, S., Elton, R.L., Members, U.P., 1987. Unified Parkinson's disease rating scale. In: Fahn, S., Marsden, C.D., Goldstein, M., Calne, D.B. (Eds.), Recent Developments in Parkinson's Disease. Macmillan Healthcare Information, Florham Park NJ.

Fervaha, G., Zakzanis, K.K., Foussias, G., Graff-Guerrero, A., Agid, O., Remington, G., 2014. Motivational deficits and cognitive test performance in schizophrenia. JAMA Psychiatry 71, 1058-1065.

Fish, B., 1987. Infant predictors of the longitudinal course of schizophrenic development. Schizophr. Bull. 13, 395-409.

Goswami, U., Sharma, A., Khastigir, U., Ferrier, I.N., Young, A.H., Gallagher, P., Thompson, J.M., Moore, P.B., 2006. Neuropsychological dysfunction, soft neurological signs and social disability in euthymic patients with bipolar disorder. Br. J. Psychiatry 188, 366-373.

Guy, W., 1976. ECDEU Assessment Manual for Psychopharmacology. US Department of Health, Education and Welfare, Rockville, MD.

Heinrichs, D.W., Buchanan, R.W., 1988. Significance and meaning of neurological signs in schizophrenia. Am. J. Psychiatry 145, 11-18.

Hirjak, D., Thomann, P.A., Kubera, K.M., Wolf, N.D., Sambataro, F., Wolf, R.C., 2015. Motor dysfunction within the schizophrenia-spectrum: a dimensional step towards an underappreciated domain. Schizophr. Res. 169, 217-233.

Isohanni, M., Murray, G.K., Jokelainen, J., Croudace, T., Jones, P.B., 2004. The persistence of developmental markers in childhood and adolescence and risk for schizophrenic psychoses in adult life. A 34-year follow-up of the Northern Finland 1966 birth cohort. Schizophr. Res. 71, 213-225.

Isvoranu, A.M., Borsboom, D., van Os, J., Guloksuz, S., 2016. A network approach to environmental impact in psychotic disorder: brief theoretical framework. Schizophr. Bull. 42, 870-873.

Janno, S., Holi, M.M., Tuisku, K., Wahlbeck, K., 2008. Neuroleptic-induced movement disorders in a naturalistic schizophrenia population: diagnostic value of actometric movement patterns. BMC Neurol. 8, 10.

Kalachnik, J.E., Sprague, R.L., 1993. The dyskinesia Identification System Condensed User Scale (DISCUS): reliability, validity, and a total score cut-off for mentally ill and mentally retarded populations. J. Clin. Psychol. 49, 177-189. 
Kay, S.R., Fiszbein, A., Opler, L.A., 1987. The positive and negative syndrome scale (PANSS) for schizophrenia. Schizophr. Bull. 13, 261-276.

Kendler, K.S., 2016. Phenomenology of schizophrenia and the representativeness of modern diagnostic criteria. JAMA Psychiatry 73, 1082-1092.

Kent, J.S., Hong, S.L., Bolbecker, A.R., Klaunig, M.J., Forsyth, J.K., O'Donnell, B.F., Hetrick, W.P., 2012. Motor deficits in schizophrenia quantified by nonlinear analysis of postural sway. PLoS One 7, e41808.

Khandaker, G.M., Stochl, J., Zammit, S., Lewis, G., Jones, P.B., 2014. A population-based longitudinal study of childhood neurodevelopmental disorders, IQ and subsequent risk of psychotic experiences in adolescence. Psychol. Med. 44, 3229-3238.

Kindler, J., Schultze-Lutter, F., Michel, C., Martz-Irngartinger, A., Linder, C., Schmidt, S.J., Stegmayer, K., Schimmelmann, B.G., Walther, S., 2016. Abnormal involuntary movements are linked to psychosis-risk in children and adolescents: results of a population-based study. Schizophr. Res. 174, 58-64.

Koning, J.P., Tenback, D.E., van Os, J., Aleman, A., Kahn, R.S., van Harten, P.N., 2010 Dyskinesia and parkinsonism in antipsychotic-naive patients with schizophrenia, first-degree relatives and healthy controls: a meta-analysis. Schizophr. Bull. 36, 723-731.

Koning, J.P., Kahn, R.S., Tenback, D.E., van Schelven, L.J., van Harten, P.N., 2011a. Movement disorders in nonpsychotic siblings of patients with nonaffective psychosis. Psychiatry Res. 188, 133-137.

Koning, J.P., Kahn, R.S., Tenback, D.E., van Schelven, L.J., van Harten, P.N., 2011b. Movement disorders in nonpsychotic siblings of patients with nonaffective psychosis. Psychiatry Res. 188, 133-137.

Koning, J.P., Tenback, D.E., Kahn, R.S., Vollema, M.G., Cahn, W., van Harten, P.N., 2011c. Movement disorders are associated with schizotypy in unaffected siblings of patients with non-affective psychosis. Psychol. Med. 41, 2141-2147.

Kostikis, N., Hristu-Varsakelis, D., Arnaoutoglou, M., Kotsavasiloglou, C., 2015. A smartphone-Based tool for assessing parkinsonian hand tremor. IEEE J. Biomed. Health Inform. 19, 1835-1842.

Lavelle, M., Healey, P.G., McCabe, R., 2013. Is nonverbal communication disrupted in interactions involving patients with schizophrenia? Schizophr. Bull. 39, 1150-1158.

Leucht, S., Kane, J.M., Kissling, W., Hamann, J., Etschel, E., Engel, R., 2005. Clinical implications of brief psychiatric rating scale scores. Br. J. Psychiatry 187, 366-371.

Logemann, H., Böcker, K., Deschamps, P., Harten, P.v., Koning, J., Kemner, C., LogemannMolnár, Z., Kenemans, L., 2017. Haloperidol 2 mg impairs inhibition but not visuospatial attention. Psychopharmacology 234, 235-244.

Lohr, J.B., Caligiuri, M.P., 2006. Abnormalities in motor physiology in bipolar disorder. J. Neuropsychiatry Clin. Neurosci. 18, 342-349.

Marcus, J., Hans, S.L., Lewow, E., Wilkinson, L., Burack, C.M., 1985. Neurological findings in high-risk children: childhood assessment and 5-year followup. Schizophr. Bull. $11,85-100$.

Marsden, C.D., 1989. Slowness of movement in Parkinson's disease. Mov. Disord. 4 (Suppl 1), S26-37.

Marvel, C.L., Schwartz, B.L., Rosse, R.B., 2004. A quantitative measure of postural sway deficits in schizophrenia. Schizophr. Res. 68, 363-372.

Mentzel, T.Q., Lieverse, R., Levens, A., Mentzel, C.L., Tenback, D.E., Bakker, P.R., Daanen, H.A., van Harten, P.N., 2016a. Reliability and validity of an instrument for the assessment of bradykinesia. Psychiatry Res. 238, 189-195.

Mentzel, T.Q., Mentzel, C.L., Mentzel, S.V., Lieverse, R., Daanen, H.A., van Harten, P.N., 2016b. Instrumental assessment of bradykinesia: a comparison between motor tasks. IEEE J. Biomed. Health Inform. 20, 521-526.

Millman, Z.B., Goss, J., Schiffman, J., Mejias, J., Gupta, T., Mittal, V.A., 2014. Mismatch and lexical retrieval gestures are associated with visual information processing, verbal production, and symptomatology in youth at high risk for psychosis. Schizophr. Res. 158, 64-68.

Mittal, V.A., Walker, E.F., 2007. Movement abnormalities predict conversion to Axis I psychosis among prodromal adolescents. J. Abnorm. Psychol. 116, 796-803.

Mittal, V.A., Tessner, K.D., McMillan, A.L., Delawalla, Z., Trotman, H.D., Walker, E.F., 2006. Gesture behavior in unmedicated schizotypal adolescents. J. Abnorm. Psychol. 115, 351-358.

Mittal, V.A., Hasenkamp, W., Sanfilipo, M., Wieland, S., Angrist, B., Rotrosen, J., Duncan, E.J., 2007a. Relation of neurological soft signs to psychiatric symptoms in schizophrenia. Schizophr. Res. 94, 37-44.

Mittal, V.A., Tessner, K.D., Trottman, H.D., Esterberg, M., Dhrub, S.H., Simeonova, D.I., McMillan, A.L., Murphy, E., Saczawa, M.E., Walker, E.F., 2007b. Movement abnormalities and the progression of prodromal symptomatology in adolescents at risk for psychotic disorders. J. Abnorm. Psychol. 116, 260-267.

Mittal, V.A., Neumann, C., Saczawa, M., Walker, E.F., 2008a. Longitudinal progression of movement abnormalities in relation to psychotic symptoms in adolescents at high risk of schizophrenia. Arch. Gen. Psychiatry 65, 165-171.

Mittal, V.A., Neumann, C., Saczawa, M., Walker, E.F., 2008b. Longitudinal progression of movement abnormalities in relation to psychotic symptoms in adolescents at high risk of schizophrenia. Arch. Gen. Psychiatry 65, 165-171.

Mittal, V.A., Daley, M., Shiode, M.F., Bearden, C.E., O'Neill, J., Cannon, T.D., 2010a. Striatal volumes and dyskinetic movements in youth at high-risk for psychosis. Schizophr. Res. 123, 68-70.

Mittal, V.A., Walker, E.F., Bearden, C.E., Walder, D., Trottman, H., Daley, M., Simone, A., Cannon, T.D., 2010b. Markers of basal ganglia dysfunction and conversion to psychosis: neurocognitive deficits and dyskinesias in the prodromal period. Biol. Psychiatry 68, 93-99.

Mittal, V.A., Dean, D.J., Pelletier, A., Caligiuri, M., 2011a. Associations between spontaneous movement abnormalities and psychotic-like experiences in the general population. Schizophr. Res. 132, 194-196.

Mittal, V.A., Jalbrzikowski, M., Daley, M., Roman, C., Bearden, C.E., Cannon, T.D., 2011b. Abnormal movements are associated with poor psychosocial functioning in adolescents at high risk for psychosis. Schizophr. Res. 130, 164-169.

Mittal, V.A., Orr, J.M., Turner, J.A., Pelletier, A.L., Dean, D.J., Lunsford-Avery, J., Gupta, T., 2013. Striatal abnormalities and spontaneous dyskinesias in non-clinical psychosis. Schizophr. Res. 151, 141-147.

Mittal, V.A., Dean, D.J., Bernard, J.A., Orr, J.M., Pelletier-Baldelli, A., Carol, E.E., Gupta, T., Turner, J., Leopold, D.R., Robustelli, B.L., Millman, Z.B., 2014. Neurological soft signs predict abnormal cerebellar-thalamic tract development and negative symptoms in adolescents at high risk for psychosis: a longitudinal perspective. Schizophr. Bull. 40, 1204-1215.

Morrens, M., Hulstijn, W., Sabbe, B., 2007. Psychomotor slowing in schizophrenia. Schizophr. Bull. 33, 1038-1053.

Neumann, C.S., Walker, E.F., 2003. Neuromotor functioning in adolescents with schizotypal personality disorder: associations with symptoms and neurocognition. Schizophr. Bull. 29, 285-298.

Obeso, J.A., Rodriguez-Oroz, M.C., Stamelou, M., Bhatia, K.P., Burn, D.J., 2014. The expanding universe of disorders of the basal ganglia. Lancet 384, 523-531.

Pappa, S., Dazzan, P., 2009. Spontaneous movement disorders in antipsychotic-naive patients with first-episode psychoses: a systematic review. Psychol. Med. 39, 1065-1076.

Peralta, V., Cuesta, M.J., 2010. The effect of antipsychotic medication on neuromotor abnormalities in neuroleptic-naive nonaffective psychotic patients: a naturalistic study with haloperidol, risperidone, or olanzapine. Prim. Care Companion J. Clin. Psychiatry 12.

Poyurovsky, M., Nave, R., Epstein, R., Tzischinsky, O., Schneidman, M., Barnes, T.R., Weizman, A., Lavie, P., 2000. Actigraphic monitoring (actigraphy) of circadian locomotor activity in schizophrenic patients with acute neuroleptic-induced akathisia. Eur. Neuropsychopharmacol. 10, 171-176.

Ridderinkhof, K.R., van den Wildenberg, W.P., Segalowitz, S.J., Carter, C.S., 2004. Neurocognitive mechanisms of cognitive control: the role of prefrontal cortex in action selection, response inhibition, performance monitoring, and reward-based learning. Brain Cogn. 56, 129-140.

Rosso, I.M., Bearden, C.E., Hollister, J.M., Gasperoni, T.L., Sanchez, L.E., Hadley, T., Cannon, T.D., 2000. Childhood neuromotor dysfunction in schizophrenia patients and their unaffected siblings: a prospective cohort study. Schizophr. Bull. 26, 367-378.

Rushworth, M.F., Walton, M.E., Kennerley, S.W., Bannerman, D.M., 2004. Action sets and decisions in the medial frontal cortex. Trends Cogn. Sci. 8, 410-417.

Schiffman, J., Walker, E., Ekstrom, M., Schulsinger, F., Sorensen, H., Mednick, S., 2004. Childhood videotaped social and neuromotor precursors of schizophrenia: a prospective investigation. Am. J. Psychiatry 161, 2021-2027.

Schiffman, J., Mittal, V., Kline, E., Mortensen, E.L., Michelsen, N., Ekstrom, M., Millman, Z.B., Mednick, S.A., Sorensen, H.J., 2015. Childhood dyspraxia predicts adult-onset nonaffective-psychosis-spectrum disorder. Dev. Psychopathol. 27, 1323-1330.

Senova, S., Querlioz, D., Thiriez, C., Jedynak, P., Jarraya, B., Palfi, S., 2015. Using the accelerometers integrated in smartphones to evaluate essential tremor. Stereotact. Funct. Neurosurg. 93, 94-101.

Simpson, G.M., Angus, J.W., 1970. A rating scale for extrapyramidal side effects. Acta Psychiatr. Scand. Suppl. 212, 11-19.

Sorensen, H.J., Mortensen, E.L., Schiffman, J., Reinisch, J.M., Maeda, J., Mednick, S.A., 2010. Early developmental milestones and risk of schizophrenia: a 45-year follow-up of the Copenhagen Perinatal Cohort. Schizophr. Res. 118, 41-47.

Stegmayer, K., Bohlhalter, S., Vanbellingen, T., Federspiel, A., Moor, J., Wiest, R., Muri, R., Strik, W., Walther, S., 2016a. Structural brain correlates of defective gesture performance in schizophrenia. Cortex 78, 125-137.

Stegmayer, K., Moor, J., Vanbellingen, T., Bohlhalter, S., Muri, R.M., Strik, W., Walther, S., 2016b. Gesture performance in first- and multiple-Episode patients with schizophrenia spectrum disorders. Neuropsychobiology 73, 201-208.

Teulings, H.L., Contreras-Vidal, J.L., Stelmach, G.E., Adler, C.H., 1997. Parkinsonism reduces coordination of fingers, wrist, and arm in fine motor control. Exp. Neurol. 146, 159-170.

Tuisku, K., Tani, P., Nieminen-von Wendt, T., von Wendt, L., Holi, M.M., PorkkaHeiskanen, T., Lauerma, H., Lindberg, N., Appelberg, B., Wahlbeck, K., 2004. Lower limb motor restlessness in Asperger's disorder, measured using actometry. Psychiatry Res. 128, 63-70.

Tuisku, K., Holi, M.M., Wahlbeck, K., Ahlgren, A.J., Lauerma, H., 2005. Actometry in measuring the symptom severity of restless legs syndrome. Eur. J. Neurol. 12, 385-387.

Walker, E.F., Savoie, T., Davis, D., 1994. Neuromotor precursors of schizophrenia. Schizophr. Bull. 20, 441-451.

Walker, E.F., Lewine, R.R., Neumann, C., 1996. Childhood behavioral characteristics and adult brain morphology in schizophrenia. Schizophr. Res. 22, 93-101.

Walker, E.F., 1994. Developmentally moderated expressions of the neuropathology underlying schizophrenia. Schizophr. Bull. 20, 453-480.

Walther, S., Mittal, V.A., 2016. Why we should take a closer look at gestures. Schizophr. Bull. 42, 259-261.

Walther, S., Morrens, M., 2015. Editorial: psychomotor symptomatology in psychiatric illnesses. Front. Psychiatry 6, 81.

Walther, S., Strik, W., 2012. Motor symptoms and schizophrenia. Neuropsychobiology 66, 77-92.

Walther, S., Horn, H., Razavi, N., Koschorke, P., Muller, T.J., Strik, W., 2009. Quantitative 
motor activity differentiates schizophrenia subtypes. Neuropsychobiology 60, 80-86. Walther, S., Vanbellingen, T., Muri, R., Strik, W., Bohlhalter, S., 2013. Impaired pantomime in schizophrenia: association with frontal lobe function. Cortex 49, 520-527.

Walther, S., Stegmayer, K., Sulzbacher, J., Vanbellingen, T., Muri, R., Strik, W., Bohlhalter, S., 2015. Nonverbal social communication and gesture control in schizophrenia. Schizophr. Bull. 41, 338-345.

Walther, S., Eisenhardt, S., Bohlhalter, S., Vanbellingen, T., Muri, R., Strik, W., Stegmayer, K., 2016a. Gesture performance in schizophrenia predicts functional outcome after 6 months. Schizophr. Bull. 42, 1326-1333.

Walther, S., Schappi, L., Federspiel, A., Bohlhalter, S., Wiest, R., Strik, W., Stegmayer, K., 2016b. Resting-State hyperperfusion of the supplementary motor area in catatonia. Schizophr. Bull.
Walther, S., 2015. Psychomotor symptoms of schizophrenia map on the cerebral motor circuit. Psychiatry Res. 233, 293-298.

Webster, D.D., 1966. Rigidity in extrapyramidal disease. J. Neurosurg. 24, 299-307.

Willems, A.E., Sommer, I.E., Tenback, D.E., Koning, J.P., van Harten, P.N., 2016. Instrumental measurements of spontaneous dyskinesia and schizotypy in subjects with auditory verbal hallucinations and healthy controls. Psychiatry Res. 244, 24-27.

Willingham, D.B., 1998. A neuropsychological theory of motor skill learning. Psychol. Rev. 105, 558-584.

Zhao, Q., Li, Z., Huang, J., Yan, C., Dazzan, P., Pantelis, C., Cheung, E.F., Lui, S.S., Chan, R.C., 2014. Neurological soft signs are not soft in brain structure and functional networks: evidence from ALE meta-analysis. Schizophr. Bull. 40, 626-641. 